\title{
Lung function in West Sussex firemen: a four year study
}

\author{
K HORSFIELD, A R GUYATT, FIONA M COOPER, MAUREEN P BUCKMAN, \\ G CUMMING
}

From the Department of Clinical Science, Cardiothoracic Institute, Midhurst, West Sussex, GU29 OBL

ABSTRACT Although firefighting is a hazardous occupation, published evidence of long term lung damage in firemen is inconsistent. A group of 96 men from the West Sussex Fire Brigade, which covers a semi-rural, semi-urban area, were followed up for between one and four years. They included 31 non-smokers, 40 smokers, and 25 ex-smokers. After four years 12 firemen had been lost to the study. A control group of 69 volunteers, consisting of non-smoking men from various other occupations, were followed up in parallel. Lung function tests, covering a wider range than has been previously used in similar studies, were repeated six monthly for two years and annually for a further two years. The results were expressed in terms of the rate of change with time of the lung function variables. Many of the variables deteriorated in both firemen and controls, but the rate of deterioration was greater in the controls than the firemen for vital capacity, ratio of residual volume to total lung capacity, $\mathrm{FEV}_{1}, \mathrm{FVC}$, peak expiratory flow (PEF), flow at $50 \%$ and $25 \%$ remaining vital capacity $\left(\dot{\mathrm{V}}_{50}\right.$ and $\dot{\mathrm{V}}_{25}$ respectively), and airways resistance (Raw). With respect to PEF, $\dot{\mathrm{V}}_{50}, \dot{\mathrm{V}}_{25}$, and Raw the control subjects deteriorated more rapidly even than the smokers and ex-smokers among the firemen. Alveolar mixing efficiency (AME), a measure of small airways function, did not change significantly over the study period in any group. Non-smoking firemen had the highest mean value of AME, decreasing through ex-smokers, controls, and smokers. We conclude that these results show no evidence of chronic lung damage in West Sussex firemen; indeed, the firemen as a group show a lower rate of deterioration of lung function with age than do the control subjects. This is attributed to the selection of fit men for the service, continued physical training, and the regular use of breathing apparatus.

Firemen as a group have better than average lung function, especially with respect to such indices as FEV $_{1}$ and FVC..$^{12}$ Although increased rates of loss of lung function have been found, ${ }^{23}$ and some have shown chronic lung damage due to exposure to smoke and fumes ${ }^{47}$ others have failed to find evidence in support of this. ${ }^{289}$ These rather varied findings have been compounded by a change in attitude to the wearing of breathing apparatus over the past 10-15 years. Whereas previously the use of breathing apparatus was considered to be unmanly and a nuisance, now it is accepted as a necessary and sensible precaution, materially contributing to the reduction of lung problems in firemen. ${ }^{8}$
All these previous studies have been carried out on city fire brigades and all but the Boston $^{8}$ have been cross sectional. We report here a four year longitudinal study of the West Sussex Fire Brigade which covers an area half rural and half industrial in character. We used a larger range of lung function tests than have been used previously, including a newer test of gas mixing efficiency, in order to look for more subtle evidence of chronic lung damage.

\section{Methods}

The study was carried out with the full and active cooperation of the West Sussex Fire Brigade and their unions with an agreement that the information gained would be confidential. 
STUDY GROUPS

From a printed list of men serving at six fire stations, chosen to represent a cross section of rural and urban fire fighting activity, 127 were randomly chosen. The study was explained to them and they were given a free choice of joining or not as they wished. Of these, 93 agreed to participate and in addition eight men who were keen to volunteer were accepted into the study, making a total of 101 . No information is available on the respiratory status of those who declined the invitation. The control group consisted of 69 male volunteers from a wide variety of occupations who were being tested at intervals as part of another study relating to the effects of tobacco smoke. Attendance for a minimum period of 18 months was required for acceptance into this group. Table 1 gives data for age and height for both groups.

All members of the control group were non-smokers whereas the firemen included smokers, ex-smokers, and non-smokers. A smoker was defined as someone who had smoked at least one cigarette a day (or its equivalent in cigars or tobacco) for the previous year. Ex-smokers had not smoked for at least one month. Never smokers (referred to here as non-smokers) had at no time fulfilled the criterion for being a smoker. Although most firemen maintained their smoking category during the study period, 24 did change their habit. These were classified according to their predominant habit during the four years, which in all but one was the same as at the time of entry to the study.

\section{TESTS PERFOR MED}

Each subject was seen and examined by a doctor, an ECG and chest $x$ ray films were taken, and the MRC questionnaire on respiratory symptoms and smoking habits was completed. At the start of the study lung function tests were done twice at an interval of about one week to provide a baseline and to familiarise the subjects with the procedures. Thereafter, tests and the questionnaire were repeated at six monthly intervals in the firemen for two years, and annually for a further two years, whereas in the controls they were continued at six monthly intervals. From the third visit onwards the questionnaire was slightly altered to ask for symptoms occurring since the previous visit.

Table 1 Mean and range of age and height in firemen and control subjects

\begin{tabular}{lrll}
\hline & No & Age (years) & Height $(m)$ \\
\hline Controls & 69 & $39.5(16-63)$ & $1.76(1.52-1.85)$ \\
Firemen: & 101 & $32.5(18-54)$ & $1.78(1.65-1.91)$ \\
Non-smokers & 33 & $32.0(18-54)$ & $1.78(1.69-1.88)$ \\
Ex-smokers & 43 & $34.3(24-51)$ & $1.77(1.68-1.91)$ \\
Smokers & 25 & $31.9(19-46)$ & $1.78(1.65-1.91)$ \\
\hline
\end{tabular}

Two groups of lung function tests were performed. The first, lung mechanics, consisted of total lung capacity (TLC), vital capacity (VC), functional residual capacity by plethysmography (FRC), residual volume (RV), RV/TLC ratio \%, forced expiratory volume in one second $\left(\mathrm{FEV}_{1}\right)$, forced vital capacity (FVC), $\mathrm{FEV}_{1} / \mathrm{FVC}$ ratio \%, peak expiratory flow (PEF), flow at $50 \%$ and $25 \%$ of vital capacity remaining during a forced expiration $\left(\dot{V}_{50}\right.$ and $\dot{V}_{25}$ respectively), airways resistance (Raw), and thoracic gas volume by plethysmography (Vtg).

The second group was related to nitrogen washout, being measured during the washout or calculated afterwards. They consisted of tidal volume ( $\mathrm{Vt} \mathrm{nw}$ ), frequency of respiration ( $\mathrm{nw}$ ), minute ventilation (MV nw), functional residual capacity (FRC nw), ventilatory efficiency (Vent eff), ventilatory dead space $(\mathrm{VdV})$, series or "anatomical" dead space (VdS), alveolar dead space (VdA), alveolar mixing efficiency (AME), and Bohr dead space (Bohr VdS). Measurement of N2 VdS, N2 VdA, and AME have been described previously by Cumming and Guyatt ${ }^{10}$ and of VdV and Vent eff by Prowse and Cumming. " Briefly, that part of the tidal volume which does not mix with alveolar gas is the ventilatory dead space. It has two components, the series dead space in the upper airways and the conducting airways, and the unmixed portion of the gas in the alveoli, termed the alveolar dead space. AME is given by

$$
\begin{aligned}
\mathrm{AME}= & {[(\text { mean Vt nw })-\mathrm{VdV}] \times 100 / } \\
& {[\text { mean Vtnw })-\mathrm{VdS}] }
\end{aligned}
$$

It is the fractional part of the tidal volume, excluding VdS, which effectively mixes with alveolar gas, expressed as a percentage. Vt nw and VdS are measured breath-by-breath during nitrogen washout with a mixture of $21 \%$ oxygen and $79 \%$ argon, and the mean values used in the calculation. $\mathrm{VdV}$ is calculated from the nitrogen decay curve. ${ }^{10}$

ANALYSIS OF THE DATA

The value of each variable which consisted of a volume measurement, or which contained a volume measurement-for example, flow-was normalised by dividing volume by height cubed. For each variable in each individual the regression against time was calculated and the mean slope of the regression line for each variable compared between subgroups. Thus we are comparing the rates of change in lung function between firemen and controls, and between the subgroups smokers, non-smokers, and ex-smokers in firemen.

Correlations were done using the parametric least squares regression. The non-parametric Mann Whitney test was used for the difference between two samples, and the sign test for the difference from zero. 
The calculations for these were performed on an Apricot F10 computer using the SPP statistical package by $\mathbf{P}$ Royston, obtained from Timberlake Clarke of Greenwich.

\section{Results}

By the end of four years 12 firemen had left the study. Four retired, two for health reasons, four resigned, one transferred, and three wished to discontinue the study. Four left in the first year, six in the second, one in the third, and one in the fourth. An additional four retired during the study period but they continued to participate. A minimum period of 12 months in the study (four lung function testing sessions) was considered necessary to calculate the regression lines; five had to be excluded on this count, leaving 96, of whom 40 were smokers, 31 non-smokers, and 25 ex-smokers.

Table 2 shows the mean slopes and whether they differ significantly from zero. Significant negative slopes were found in both firemen and controls for VC, $\mathrm{FEV}_{1}, \mathrm{FVC}, \dot{\mathrm{V}}_{50}, \mathrm{Vt} \mathrm{nw}, \mathrm{FRC} \mathrm{nw}, \mathrm{VdV}, \mathrm{VdS}$, and Bohr $\mathrm{VdS}$, with significant positive slopes for RV/TLC and Raw. Firemen also had significant negative slopes for $\mathrm{FRC}, \mathrm{FEV}_{1} / \mathrm{FVC}$ ratio, and VdA, and controls for TLC, PEF, and $\dot{V}_{25}$. The slopes for Vent eff and AME were not significant in either group. Smokers had the highest rate of loss of TLC and FRC. Although their rate of loss of VC, FEV , and FVC, and their rate of increase of Raw, were the highest among firemen, nevertheless they were lower than in the controls.

Ex-smokers showed the lowest rate of loss of FEV and FVC and of increasing PEF.

In non-smoking firemen RV/TLC showed the lowest rate of increase. Interestingly and surprisingly at first sight, they also had the highest rate of loss of $\mathrm{FEV}_{1} / \mathrm{FVC}$, whereas smokers had the lowest. This was beause in smokers the fall in FVC was relatively greater than the fall in non-smokers, and had a greater effect on the ratio than did the smaller fall in FEV

Table 3 shows the significance of the difference in mean slopes between the groups and subgroups. The differences are most pronounced between firemen and controls, firemen having the lower rate of loss of function with respect to VC, RV/TLC, FEV, FVC, PEF, $\dot{\mathrm{V}}_{50}, \dot{\mathrm{V}}_{25}$, and Raw. With respect to PEF, $\dot{\mathrm{V}}_{50}, \dot{\mathrm{V}}_{25}$, and Raw the controls deteriorated more rapidly than even the smokers and ex-smokers among firemen. In ex-smokers FRC, PEF, and Vtg increased whereas they fell in non-smokers. The lower slopes for FEV, and FVC in ex-smokers fail to reach a statistically significant difference from those in other firemen.

Regarding AME, no significant change with time was noted. It was therefore decided to take the mean value of all the results for each individual and to compare the subgroups using these mean values. Table 4 shows the results obtained and table 5 the significance of the differences. The mean value is highest in the non-smoking firemen, falling through ex-smokers, controls, and smokers in that order.

Table 2 Mean values of slope (change/year) of regression equations for each variable against time and significance of the difference of the mean slope from zero

\begin{tabular}{|c|c|c|c|c|c|c|c|c|c|c|c|}
\hline \multirow[b]{3}{*}{ Variable } & \multirow[b]{3}{*}{ Units } & \multirow{2}{*}{\multicolumn{2}{|c|}{ Controls }} & \multirow{2}{*}{\multicolumn{2}{|c|}{ All firemen }} & \multicolumn{6}{|l|}{ Firemen } \\
\hline & & & & & & \multicolumn{2}{|c|}{ Non-Smokers } & \multicolumn{2}{|c|}{ Ex-Smokers } & \multicolumn{2}{|l|}{ Smokers } \\
\hline & & Mean & Sig & Mean & Sig & Mean & Sig & Mean & Sig & Mean & Sig \\
\hline $\begin{array}{l}\text { TLC } \\
\text { VC } \\
\text { FRC } \\
\text { RV/TLC } \\
\text { FEV } \\
\text { FVC } \\
\text { FEV } / \text { FVC } \\
\text { PEF } \\
\dot{V}_{\text {so }} \\
\dot{V}_{25} \\
\text { Raw } \\
\text { Vtg } \\
\text { Vt nw } \\
\text { f nw } \\
\text { MV nw } \\
\text { FRC nw } \\
\text { Vent eff } \\
\text { VdV } \\
\text { N }_{2} \text { VdS } \\
N_{2} \text { VdA } \\
\text { AME } \\
\text { Bohr VdS }\end{array}$ & $\begin{array}{l}1 / \mathrm{m}^{3} \\
1 / \mathrm{m}^{3} \\
1 / \mathrm{m}^{3} \\
\% \\
1 / \mathrm{m}^{3} \\
1 / \mathrm{m}^{3} \\
\% \\
1 / \mathrm{s} / \mathrm{m}^{3} \\
1 / \mathrm{s} / \mathrm{m}^{3} \\
1 / \mathrm{s}^{3} \mathrm{~m}^{3} \\
\mathrm{Cm} \mathrm{H}_{2} \mathrm{Ol} / \mathrm{s} / \mathrm{m}^{3} \\
1 / \mathrm{m}^{3} \\
\mathrm{ml} / \mathrm{m}^{3} \\
\mathrm{~min} \\
1 / \mathrm{min}^{1} / \mathrm{m}^{3} \\
1 / \mathrm{m}^{3} \\
\% \\
\mathrm{ml} / \mathrm{m}^{3} \\
\mathrm{ml} / \mathrm{m}^{3} \\
\mathrm{ml} / \mathrm{m}^{3} \\
\% \\
\mathrm{ml} / \mathrm{m}^{3}\end{array}$ & $\begin{array}{l}-0.0085 \\
-0.0187 \\
-0.0042 \\
+0.920 \\
-0.0184 \\
-0.0206 \\
-0.261 \\
-0.0336 \\
-0.0273 \\
-0.0050 \\
+0.0943 \\
-0.0065 \\
-7.47 \\
+0.254 \\
-0.0531 \\
-0.0154 \\
-0.394 \\
-2.93 \\
-1.03 \\
-1.90 \\
-0.246 \\
-1.23\end{array}$ & $\begin{array}{l}* \\
* * \\
* * \\
* * \\
* * \\
* * \\
* * \\
* * \\
* * \\
* * \\
* \\
* * \\
* * \\
* * \\
* *\end{array}$ & $\begin{array}{l}-0.0082 \\
-0.0111 \\
-0.0071 \\
+0.412 \\
-0.0116 \\
-0.0122 \\
-0.268 \\
+0.0052 \\
-0.0067 \\
+0.0020 \\
+0.0431 \\
-0.0053 \\
-0.362 \\
+0.045 \\
-0.0412 \\
-0.0145 \\
+0.193 \\
-1.96 \\
-1.08 \\
-0.82 \\
+0.210 \\
-1.27\end{array}$ & $\begin{array}{l}* * \\
* \\
* * \\
* * \\
* * \\
* \\
* * \\
* * \\
* * \\
* * \\
* * \\
* * \\
* * \\
* \\
* *\end{array}$ & $\begin{array}{l}-0.0088 \\
-0.0083 \\
-0.0088 \\
+0.149 \\
-0.0118 \\
-0.0117 \\
-0.355 \\
-0.0056 \\
-0.0142 \\
-0.0055 \\
+0.0295 \\
-0.0082 \\
-4.09 \\
+0.142 \\
-0.0451 \\
-0.0169 \\
-0.055 \\
-1.86 \\
-1.36 \\
-0.72 \\
-0.430 \\
-1.72\end{array}$ & $\begin{array}{l}* * \\
* * \\
* * \\
* \\
* * \\
\\
* * \\
* \\
* * \\
* \\
* \\
*\end{array}$ & $\begin{array}{l}-0.0034 \\
-0.0111 \\
+0.0035 \\
+0.603 \\
-0.0097 \\
-0.0093 \\
-0.307 \\
+0.0343 \\
-0.0079 \\
+0.0076 \\
+0.0387 \\
+0.0070 \\
-3.80 \\
-0.031 \\
-0.0522 \\
-0.0069 \\
-0.131 \\
-1.72 \\
-0.97 \\
-0.75 \\
-0.170 \\
-1.13\end{array}$ & $\begin{array}{l}* * \\
* \\
* * \\
* \\
* \\
* * \\
* * \\
* *\end{array}$ & $\begin{array}{l}-0.0107 \\
-0.0133 \\
-0.0125 \\
+0.497 \\
-0.0125 \\
-0.0143 \\
-0.176 \\
-0.0046 \\
-0.0002 \\
+0.0044 \\
+0.0564 \\
-0.0108 \\
-3.14 \\
+0.018 \\
-0.0313 \\
-0.0175 \\
+0.587 \\
-2.20 \\
-0.93 \\
-0.93 \\
+0.643 \\
-1.01\end{array}$ & $\begin{array}{l}* * \\
* \\
* * \\
* *\end{array}$ \\
\hline
\end{tabular}

Sig = Significance of difference of mean slope from zero.

$*=p<0.05, * *=p<0.01$. Blank = not significant. 
Table 3 Significance of difference between groups for the mean values of slopes shown in table 2

\begin{tabular}{|c|c|c|c|c|c|c|c|}
\hline \multirow[b]{2}{*}{ Variable } & \multicolumn{3}{|c|}{ Controls v } & \multirow[b]{2}{*}{ Smokers } & \multicolumn{2}{|c|}{ Non-smokers $v$} & \multirow{2}{*}{$\begin{array}{l}\text { Ex-smokers v } \\
\text { Smokers }\end{array}$} \\
\hline & All firemen & Non-smokers & Ex-smokers & & Ex-smokers & Smokers & \\
\hline $\begin{array}{l}\text { TLC } \\
\text { VC } \\
\text { FRC } \\
\text { RV/TLC } \\
\text { FEV } \\
\text { FVC } \\
\text { FEV, FVC } \\
\text { PEF } \\
\dot{V}_{\text {so }} \\
\dot{V}_{25} \\
\text { Raw } \\
\text { Vtg } \\
\text { Vent eff }\end{array}$ & $\begin{array}{l}* \\
* \\
* * \\
* * \\
* * \\
* * \\
* * \\
* *\end{array}$ & $\begin{array}{l}* * \\
* \\
* \\
* * \\
* \\
* \\
* *\end{array}$ & $\begin{array}{l}* \\
* \\
* * \\
* * \\
* * \\
* * \\
*\end{array}$ & $\begin{array}{l}* \\
* * \\
* * \\
* \\
*\end{array}$ & $* *$ & & $*$ \\
\hline
\end{tabular}

Controls and smokers are significantly lower than non-smoking firemen, and smokers are also significantly lower than ex-smokers.

Because AME is not widely used, not a great deal is known about its relation to other tests of lung function. We therefore took the opportunity to correlate it with five indices of gas flow-namely, $\mathrm{FEV}_{1}, \mathrm{PEF}, \dot{\mathrm{V}}_{50}, \dot{\mathrm{V}}_{25}$, and specific airways conductance SGaw. $\dot{V}_{25}$ is possibly an index of small airways flow, whereas the others are predominantly indices of large airway function. The correlations were performed using pairs of values for the variables from every session and pooling the data for firemen and controls. Table 6 shows the values of $r, p$, and slopes of the regression lines. A significant positive correlation was found with all except SGaw; however, the slopes and the values of $r$ are so small that at the most all that can be said is that there is a slight underlying trend affecting both variables. Thus although the correlations are statistically significant, they do not appear to be of any physiological importance.

The results from four subgroups of firemen were looked at separately. These were: (1) the eight volunteers; (2) five who had fewer than four studies and for whom regression equations were therefore not calculated; (3) 12 who left the study in under four years, inclusive of subgroup (2); (4) 22 officers higher than sub-officer. If any of the first three subgroups differed from the remainder bias might be introduced into the results. The officers in subgroup (4) are usually less

Table 4 Mean and standard deviation of alveolar mixing efficiency in firemen and controls

\begin{tabular}{lll}
\hline & Mean $\%$ & $S D$ \\
\hline Controls & $67 \cdot 6$ & $5 \cdot 8$ \\
Firemen: & $67 \cdot 9$ & $5 \cdot 1$ \\
Non-smokers & $71 \cdot 1$ & $3 \cdot 9$ \\
Ex-smokers & $68 \cdot 3$ & $3 \cdot 1$ \\
Smokers & 652 & $5 \cdot 5$ \\
\hline
\end{tabular}

actively concerned in actually fighting fires, although they do supervise on site at incidents and may therefore be exposed to smoke and fumes. Each subgroup was compared in turn with all other firemen with respect to age, height, years of service, and lung function tests at session 1 . The volunteers averaged 8.7 years older $(p<0.001)$, had served an average of $7 \cdot 1$ years longer $(p<0.001)$, and had a mean MVnw 0.18 $\mathrm{l} / \mathrm{min} / \mathrm{m}^{3}$ higher. In the officers mean $\dot{\mathrm{V}}_{25}$ was $0.016 \mathrm{l} /$ $\mathrm{min} / \mathrm{m}^{3}$ higher $(\mathrm{p}<0.05)$. No other significant differences were observed. Thus there was little evidence of bias resulting from either the volunteers or those who left the study being different from the rest of the group.

\section{Discussion}

In choosing the firemen for this study the objective had been to make a random selection of officers and men from different areas. Nevertheless, a free choice of acceptance or refusal to participate had to be given and in the event 34 randomly chosen men did in fact refuse. This partial self selection could have biased the results if those who refused had an excess of respiratory abnormalities. In addition, the eight volunteers might have been especially fit. No information is available regarding the lung function status of those who refused to participate, but the volunteers showed no appreciable difference from the remainder of the group, apart from age and duration of service.

Table 5 Significance of difference between groups for alveolar mixing efficiency

\begin{tabular}{llll}
\hline & Controls & Non-smokers & Smokers \\
\hline Ex-smokers & NS & NS & $\mathrm{p}<0.01$ \\
Smokers & NS & $\mathrm{p}<0.001$ & \\
Non-smokers & $\mathrm{p}<0.0001$ & & \\
All firemen & NS & & \\
\hline NS $=$ Not significant at $5 \%$. & &
\end{tabular}


Table 6 Values of slopes, $r$, and p for correlation between alveolar mixing efficiency and five selected flow variables. Pooled data for firemen and control subjects

\begin{tabular}{lccccl}
\hline & $F E V_{1}$ & \multicolumn{1}{l}{$P E F$} & \multicolumn{1}{l}{$\dot{V}_{\text {so }}$} & \multicolumn{1}{l}{$\dot{V}_{25}$} & \multicolumn{1}{l}{ SGaw } \\
\hline Slope & 0.0010 & 0.0027 & 0.0014 & 0.0006 & -0.0012 \\
$\mathrm{r}$ & 0.10 & 0.08 & 0.07 & 0.06 & -0.03 \\
$\mathrm{p}$ & $<0.01$ & $<0.01$ & $<0.05$ & $<0.001$ & $>0.05$ \\
\hline
\end{tabular}

$r=$ Correlation coefficient $; p=$ probability; SGaw $=$ specific airways conductance. Slope is that of the regression of the flow variable on alveolar mixing efficiency. The units are given in table 2, except for $\mathrm{SGaw}$ which are $\mathrm{s}^{-1} / \mathrm{cmH}_{2} \mathrm{O}$.

Calculation of the rate of change of a variable required a minimum of four data points over one year. Five firemen dropped out before completing one year, leaving 96 men for whom regression equations could be calculated. The loss of this small group would be unlikely to bias the results to any great degree and in any case they had been shown not to differ from the remainder of the group.

Lung volumes are a function of body size, and various means of normalising for this have been used, including dividing volume by height, ${ }^{2}$ height, ${ }^{3}$ and height. ${ }^{42-14}$ We chose to divide by height, ${ }^{3}$ partly because this might be expected to be the most closely related to body volume. In practice it makes little difference to the comparison between our groups which correction is used because their heights are similar.

A difficulty arises from the fact that the mean age of the control group is seven years greater than that of the firemen. Provided that the rate of change of a variable does not change with age this will not be a problem. Fletcher et al found an accelerating deterioration of FEV , with age in smokers,${ }^{14}$ and to test this we plotted FEV , slope against age for each subgroup and all groups combined. Only in the smokers did slope increase with age, the change being $-0.8 \mathrm{ml} / \mathrm{m}^{3}$ year $^{2}$.

In general the results show that lung volumes, flows, and dead spaces all decrease with age whereas RV/ TLC increases, both in firemen and controls. The fall in $\mathrm{Vt} \mathrm{nw}$, and hence MV nw, was most probably due to familiarisation with the tests over a period rather than a true fall in resting tidal volume. Neither Vent eff nor AME showed a significant change with time, even though the mean values in the groups differed significantly. Either the change in these variables in someone who starts or stops smoking is gradual, or there is relatively rapid stepwise change followed by a plateau at a new level. Other studies on smoking at this institute do not support the stepwise change hypothesis, so the response to changes in smoking habit is probably rather gradual. Smokers had the lowest value whereas non-smoking and ex-smoking firemen had higher values than the control subjects. The absence of any physiologically significant relation between indices of flow, which are primarily measures of large airway function, and AME is suggestive evidence that AME is a measure of small airway function. The lower values found in the smokers therefore suggest the possibility of small airways damage, whereas the higher values found in firemen who are not currently smoking show that they have better gas mixing than the control subjects.

Among the firemen, smokers had the fastest rate of deterioration of TLC, VC, FRC, FEV, FVC, and Raw, indicating the long term damage to their lungs produced by smoking. Nevertheless, the control subjects lost FEV, $\mathrm{FVC}$, and VC, and increased RV/ TLC, faster than did smoking firemen. Thus the physical activity and training that firemen are required to undertake does seem to maintain their fitness, at least as judged by lung function.

Ex-smokers had the lowest rate of loss of $\mathrm{FEV}_{1}$ and FVC, although the mean values hide a wide range of responses. In some FEV ${ }_{1}$ and FVC increased over the study period, whereas in others deterioration continued at the same rate as in smokers. Fletcher $e a^{14}$ and Nemery et al $^{15}$ also observed diminished rates of loss in ex-smokers, and this may indicate that at least part of the damage caused by smoking is reversible, although Fletcher et al denied this interpretation of their own results.

The absolute values for the rate of loss of $\mathrm{FEV}_{1}$ reported here are high compared with those found by other workers. Fletcher $e t$ al found a mean fall of $30 \mathrm{ml}$ a year, which they corrected to $45 \mathrm{ml}$ a year,,$^{14}$ whereas Cotes quotes 28 and $31 \mathrm{ml}$ a year uncorrected for height. ${ }^{12}$ These rates would correspond to approximately $5 \mathrm{ml} / \mathrm{m}^{3}$ a year in the firemen, compared with $11.8 \mathrm{ml} / \mathrm{m}^{3}$ a year actually observed. This phenomenon of an apparently rapid fall in $\mathrm{FEV}_{1}$ over a short period has been seen in other studies. ${ }^{216}$ It has been attributed to secular changes in the measurement of the indices, but the fact that it has been observed by several investigators suggests that some other factor might be involved as well, and this may be worthy of further investigation. Fletcher $e t$ al found a variable rate of change, falling rapidly at some times and hardly at all at others, so that they needed a longitudinal study of eight years in order to obtain a stable value. ${ }^{14}$

This study has shown that lung function in a sample of West Sussex firemen deteriorates with age more slowly than in a group of non-smoking control subjects. Even in firemen who smoke, some of the tests of flow and lung volume decline more slowly than in the control subjects. Alveolar mixing efficiency, a test of small airways function, is higher in the firemen than in the controls, but is lowest in the smokers.

Thus no evidence has come to light to suggest that lung function in West Sussex firemen is adversely affected by their occupation, at least in the long term. 
This statement in no way excludes the possibility of acute effects arising from inhalation of smoke and fumes, which was not the subject of this study. Ten to 15 years ago breathing apparatus was used only when absolutely necessary and difficulties in its preparation and servicing also militated against its use. More recently, especially with the increasing danger of exposure to toxic fumes during the combustion of modern plastics, breathing apparatus is used routinely. Our results confirm that overall it is protecting the firemen. One factor which could affect these conclusions is the so called "healthy worker" effect. This occurs if men whose lungs are adversely affected are removed from the group fighting fires, resulting in those that remain being the healthy ones. In the West Sussex Fire Brigade this is unlikely. Men with health problems are not given the opportunity to move to a job which does not involve fire fighting. Furthermore, an examination of the stated diagnoses in the 41 cases of retirement for health reasons from 1976 to 1985 showed two cases of asthma and one of chronic bronchitis from a brigade of 375 full time and 273 part time men. In only one of these was there any suggestion that exposure to fumes had played a part in the genesis of the problem.

West Sussex firemen are a specially selected group, being self selected on application to join the service and selected on entry from a waiting list. As a consequence they are fitter than average and maintain their fitness by regular physical training. This coupled with the regular use of breathing apparatus, probably explains their above average lung function and its slower rate of deterioration with age.

In addition to the Colt Foundation, who contributed the major part of the funding for this study, we also wish to thank the following companies for financial support: A Grantham, British Petroleum, Chubb Fire Security, Helmets, Interlink Import-Export, Mather and Platt, Merryweather and Sons, Siebe Gorman, Metal Box, and Shell UK.
Requests for reprints to: Dr K Horsfield.

\section{References}

1 Sidor R, Peters JM. Fire fighting and pulmonary function. Am Rev Respir Dis 1974;109:249-54.

2 Douglas DB, Douglas RB, Oakes D, Scott G. Pulmonary function in London firemen. Br J Ind Med 1985;42:55-8.

3 Sparrow D, Bosse R, Rosner B, Weiss ST. The effect of occupational exposure on pulmonary function. Am Rev Respir Dis 1982;125:319-22.

4 Musk AW, Smith TJ, Peters JM, McLaughlin E. Pulmonary function in fire fighters: acute changes in ventilatory function and their correlates. $\mathrm{Br} J$ Ind Med 1979;36:29-34.

5 Axford AT, McKerrow CB, Parry Jones A, Le Quesne PM. Accidental exposure to isocynate fumes in a group of firemen. Br J Ind Med 1976;33:65-71.

6 Loke J, Farmer W, Matthay RA, Putmen CE, Walker Smith GJ. Acute and chronic effects of fire fighting on pulmonary function. Chest 1980;77:369-73.

7 Unger KM, Snow RM, Mestas JM, Miller WC. Smoke inhalation in firemen. Thorax 1980;35:838-42.

8 Musk AW, Peters JM, Bernstein L, Rubin C, Monroe CB. Pulmonary function in fire fighters: a six-year follow-up in the Boston Fire Department. Am J Ind Med 1982;3:3-9.

9 Tashkin DP, Genovesi MG, Chopra S, Coulson A, Simmons M. Respiratory status of Los Angeles firemen. Chest 1977;71: 445-9.

10 Cumming G, Guyatt AR. Alveolar gas mixing efficiency in the human lung. Clin Sci 1982;62:541-7.

11 Prowse K, Cumming G. Effects of lung volume and disease on the lung nitrogen decay curve. J Appl Physiol 1973;34:22-33.

12 Cotes JE. Lung function. Oxford: Blackwell Scientific Publications, 1979.

13 Altman PL, Dittmar DS, comps. Respiration and circulation. (Biological handbook series.) Bethesda: Federation of American Societies for Experimental Biology, 1971.

14 Fletcher C, Peto R, Tinker C, Speizer FE. The natural history of chronic bronchitis and emphysema. Oxford: Oxford University Press, 1976

15 Nemery B, Moavero NE, Brasseur L, Stanescu SC. Changes in lung function after smoking cessation: an assessment from a cross-sectional survey. Am Rev Respir Dis 1982;125:122-4.

16 Peters JM, Theriault GP, Fine LJ, Wegman DH. Chronic effect of firefighting on pulmonary function. $N$ Engl J Med 1974; 291:1320-2. 